\title{
Hidatidose policística: Relato de dois casos procedentes de Sena Madureira, Acre, na Amazônia brasileira
}

\author{
Polycystic hydatid disease: Report of two cases from the city of Sena \\ Madureira, Acre, in Brazilian Amazon \\ Ricardo Pastore' ${ }^{1}$, Lúcia H. Vitali ${ }^{2}$, Judith Weirich ${ }^{3}$, Anna C. Tojal ${ }^{3}$, \\ Vanize de Oliveira Macedo' e Aluízio Prata ${ }^{4}$
}

Resumo Dois casos de hidatidose policística (HP) são relatados, oriundos do mesmo município da região amazônica brasileira (Sena Madureira, Acre). Ambos tiveram a mesma apresentação e evolução clínica ao longo de dois anos de acompanhamento. Inicialmente os pacientes queixaram-se de dor abdominal no andar superior ou no hipocôndrio direito e apresentaram icterícia obstrutiva, febre, aumento de volume abdominal e emagrecimento. Por exame de imagem, além de esplenomegalia, cistos múltiplos e coalescentes foram detectados no fígado. Amostras de soro foram reagentes por contraimunoeletroforese. $O$ tratamento com albendazol resultou em melhora parcial, com alívio sintomático e redução no tamanho das lesões. Este relato reforça a importância de estudos clínico-epidemiológicos da hidatidose policística na região amazônica brasileira, especialmente no município de Sena Madureira, onde outros pacientes com HP podem estar sem diagnóstico. Palavras-chaves: Hidatidose policística. Hidatidose. Echinococcus vogeli. Amazônia brasileira.

Abstract Two cases of Polycystic hydatid disease $(\mathrm{PH})$ are reported from the same municipal district of the Brazilian Amazon region (Sena Madureira, Acre). Both had a similar clinical presentation and course over two years of follow-up. Initially the patients complained of pain in the right hypochondrium or upper abdomen and presented obstructive jaundice, fever, increased abdominal volume and weight loss. By image analysis, in addition to splenomegaly, multiple and coalescent cysts were detected in the liver. Serum samples were reactive by counterimmunoelectrophoresis. Treatment with albendazole resulted in partial improvement, with symptomatic relief and reduction in size of the lesions. This report stresses the importance of performing clinical-epidemiological studies of polycystic hydatid disease in the Brazilian Amazon and especially in the municipality of Sena Madureira where many other cases of $\mathrm{PH}$ may remain undiagnosed.

Key-words: Polycystic hydatid disease. Hydatidosis. Echinococcus vogeli. Brazilian Amazon.

\footnotetext{
1. Núcleo de Medicina Tropical da Universidade de Brasília, Brasília, DF.. 2. Hospital das Clínicas da Faculdade de Medicina da Universidade de São Paulo, Ribeirão Preto, SP. 3. Hospital Geral de Clínicas de Rio Branco. 4. Faculdade de Medicina do Triângulo Mineiro, Uberaba, MG.

Endereço para correspondência: DR. Ricardo Pastore. Núcleo de Medicina Tropical e Nutrição/UnB. Caixa Postal 4517, 70919-970 Brasília, DF. Tel: 550612735008 ; Fax: 550612732811

e-mail:tropical@unb.br

Recebido para publicação em 14/8/2001.
} 
Desde 1972, com a descrição do Echinococcus vogeli (Rausch e Bernstein), surgiu na literatura especializada um crescente número de relatos de casos dessa doença ${ }^{1256810111416}$ A nova enfermidade passou a ser denominada de hidatidose policística (HP), semelhante à hidatidose unilocular, devido ao seu curso prolongado e aos locais de infecção no homem, embora com os aspectos morfológicos das lesões, nos órgãos alvos, diferenciados, ocorrendo em cadeias de hidátides policísticas.

O objetivo do presente trabalho é o de relatar dois casos de hidatidose policística, no município de Sena Madureira (Acre), na Amazônia brasileira (Figura 1).

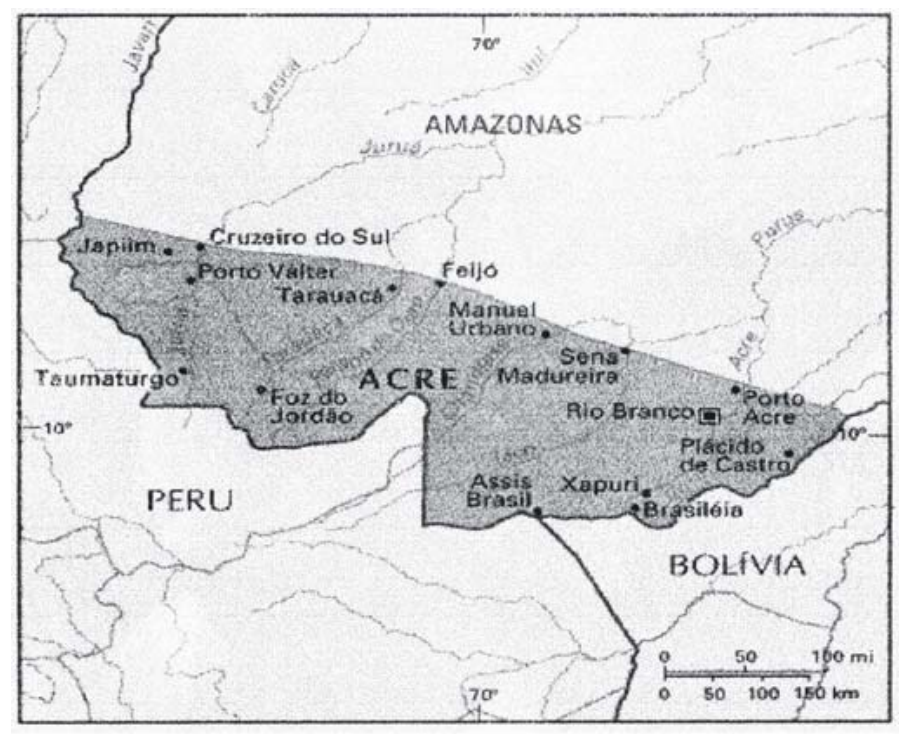

Figura 1 - Localização do Estado do Acre.

\section{RELATOS DE CASOS}

Caso 1: O.P.L, 28 anos, masculino, pardo, casado, lavrador, natural e procedente da área rural do município de Sena Madureira. O paciente nunca saiu do Estado, tendo viajado apenas para Rio Branco motivado pelo tratamento especializado da enfermidade em questão. Possui o hábito de ingerir carne de caça, tendo visto, diversas vezes, o fígado e as vísceras de animais silvestres, principalmente da paca, infestados de pequenos cistos de conteúdo claro. Possui cão que se alimenta comumente com as vísceras de animais silvestres. Antes do quadro atual, não apresentava qualquer sintomatologia. Nega tabagismo e etilismo.

Em janeiro de 1999, iniciou a doença com quadro de dor abdominal epigástrica, em aperto, com irradiação para hipocôndrio direito, sem fatores atenuantes ou agravantes. No início, as dores eram episódicas, diminuindo o intervalo entre os episódios, até se tornarem constantes. No final do sexto mês, associou-se à dor, lento aumento do volume abdominal e massa epigástrica endurecida; concomitantemente surgiu icterícia progressiva, com perda de coloração fecal e colúria, febre e prurido generalizado. Procurou, então, o serviço médico local, tendo como principal hipótese diagnóstica hepatite viral, e foi-lhe recomendando repouso domiciliar e uso de sintomáticos. Como não houve melhora, após vinte dias de evolução, foi encaminhado ao Serviço de Infectologia do Hospital Geral de Clínicas de Rio Branco (HGCRB), onde permaneceu internado por um mês, para elucidação diagnóstica e tratamento. Á admissão, apresentava também queixas de náuseas, vômitos e emagrecimento não quantificado. Ao exame físico, icterícia (4+/4), febre, fígado palpável a $10 \mathrm{~cm}$ do apêndice xifóide, levemente endurecido e baço palpável apenas à inspiração profunda. Foram realizadas ultra-sonografia abdominal (US) e tomografia computadorizada (CT) que revelaram: hepatomegalia com a presença de cisto volumoso e pequenos cistos periféricos no lobo direito, fortalecendo a hipótese de HP (Figura 2). Através da técnica de contraimunoeletroforese obteve-se reação sorológica positiva com titulação de 1/8. Em 2001, o paciente mantém acompanhamento ambulatorial no serviço especializado, em uso de albendazol (400mg/dia), com melhora parcial, mas, com recidiva após curto período de suspensão da droga. Apesar do quadro clínico estável, mantém hepatomegalia, queixa de dor epigástrica ocasionalmente, e prurido principalmente em membros superiores, com limitação das atividades laborais. 
Caso 2: N.V.A. 17 anos, feminina, parda, solteira, do lar, natural do município de Sena Madureira, zona urbana, mudando-se durante a infância para o Seringal Descanso, no rio Purus (zona rural), onde vive desde então. Relata não ter o hábito de ingerir carne de animais silvestres, mas assinala o contato domiciliar com cães alimentados com vísceras desses animais. Sua genitora informa ter observado com freqüência as vísceras, principalmente de paca, infestadas por cistos. Não relata outras doenças, nem casos semelhantes na família.Nega tabagismo e etilismo.

Em agosto de 1999, queixou-se de dor em hipocôndrio direito, do tipo cólica, sem irradiação, seguida de icterícia progressiva associada à hipocolia fecal e colúria. Inicialmente afebril, evoluiu com febre, aumento do volume abdominal, e tosse não produtiva, após o segundo mês. Procurou o serviço médico local, que a encaminhou para avaliação do Serviço de Infectologia do HGCRB. À admissão apresentava icterícia (4+/4), febre, emagrecimento não quantificado, déficit de atenção com sinais de sonolência, lesões pruriginosas em todo o corpo, tosse não produtiva persistente, com exame pulmonar e Rx de tórax sem

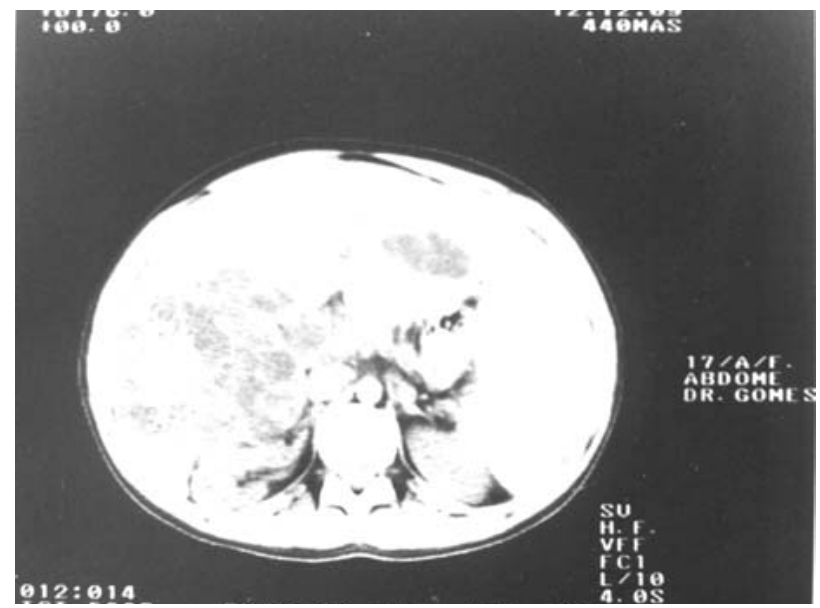

Figura 2 - Volumosa formação cística em lobo direito hepático, com cistos periféricos menores e alguns coalescentes, (CT). alterações. Abdome flácido, porém aumentado às custas de massa de consistência endurecida no epigástrio, fígado a $9 \mathrm{~cm}$ do rebordo costal direito e $16 \mathrm{~cm}$ do apêndice xifóide. Durante a investigação, foi estabelecido o diagnóstico de HP, tendo como suporte o quadro clínico e a epidemiologia, associados ao US e CT (Figura 3). Recebeu alta com orientação para acompanhamento ambulatorial e início de quimioterapia com albendazol (10mg/kg/dia). Retornou ao serviço após cinco meses, com recidiva do quadro, associada à falta de adesão ao tratamento quimioterápico e ao acompanhamento ambulatorial. Nesta ocasião, permaneceu internada por período prolongado (54 dias), devido à suspeita de infecção bacteriana associada à HP. Fez uso de albendazol, com melhora progressiva do quadro, tendo então recebido alta. Em 2001, vem apresentando novo episódio de icterícia, aumento de volume abdominal e tosse não produtiva, após suspensão do tratamento durante 30 dias. Comparece às consultas ambulatoriais de maneira irregular. Através da técnica de contraimunoeletroforese obteve-se reação sorológica positiva com titulação de 1/16.

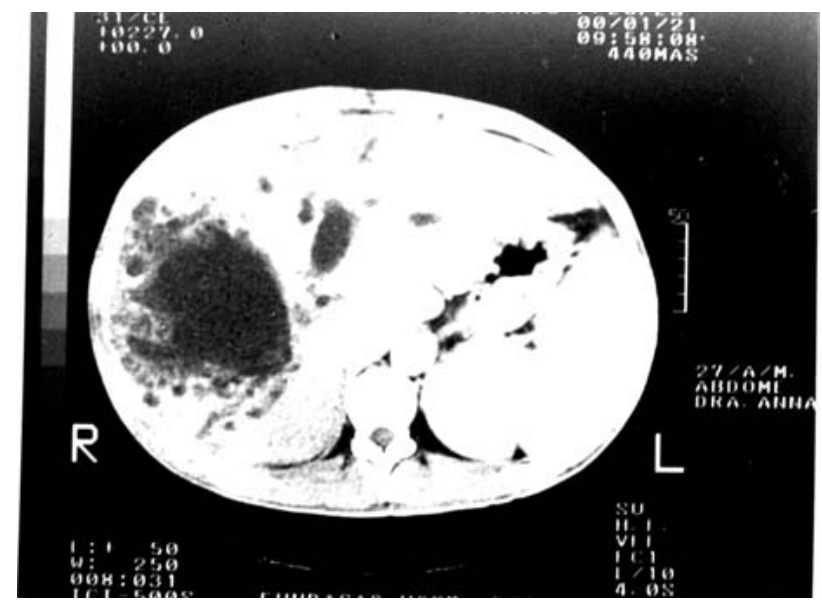

Figura 3 - Múltiplos cistos coalescentes em lobo direito hepático, com calcificaçoes grosseiras de permeio. Esplenomegalia, (CT).

\section{DISCUSSÃO}

A HP tem sido encontrada em áreas silvestres das Américas. A primeira publicação na literatura foi feita em $1979{ }^{9}$ por D'Alessandro e cols. que relataram 14 casos em três diferentes países (Equador, Colômbia e Panamá). Em 1997 D’Alessandro publicou uma metanálise de relatos de casos onde compilou 24 casos brasileiros sendo 7 no Acre. No mesmo artigo, em forma de adendo, refere a existência de mais 14 casos oriundos do estado do Pará ainda não publicados. Desde 1997, mais três casos foram relatados ${ }^{1219}$, e posteriormente outros, totalizando 72 casos em onze países.
O entendimento que se tem hoje do ciclo biológico deste parasita se deve à observação sistemática dos animais silvestres da Amazônia colombiana no decorrer de 18 anos (1962 a 1979) encontrando-se $96(29,5 \%)$ pacas (Cuniculus paca) contaminadas pelo Echinococcus sp de um total de 325 estudadas $^{8}$. Pode-se dessa forma, ressaltar a importância da paca como hospedeiro intermediário da HP, inferência esta sustentada pela observação epidemiológica do contato, comumente presente, dos doentes com cães domésticos alimentados comvísceras desses animais. 
A epidemiologia é de grande importância na suspeita diagnóstica. A origem do indivíduo de áreas silvestres e o hábito da caça de subsistência apresenta associação com a ocorrência da moléstia. A HP costuma manifestar seus sintomas igualmente em homens e mulheres entre a $2^{\mathrm{a}}$ e a $3^{\mathrm{a}}$ ou $4^{\mathrm{a}}$ décadas de vida, faixas etárias da população economicamente ativa, acarretando um prejuízo sócio-econômico apreciável, considerando que os casos conhecidos constituem apenas a manifestação inicial, sem ainda o conhecimento da freqüência de assintomáticos. O curso crônico da doença debilita de forma lenta, e com deterioração do estado geral do doente. Os tratamentos apresentados na literatura, apesar de alentadores, não são definitivos ${ }^{15} 16$.

A HP deve ser considerada como diagnóstico diferencial, em enfermidades que se manifestem por massas policísticas. As manifestações clínicas surgem, em decorrência do efeito compressivo dos cistos, contra as estruturas anatômicas adjacentes. O fígado é o órgão mais comumente afetado ( $80 \%$ ) e, portanto, a dor abdominal, a hepatomegalia e a icterícia colestática, aparecem como as manifestações mais comuns ${ }^{618}$. Cada vez mais se tem reconhecido esta enfermidade como diagnóstico diferencial de neoplasia e outras doenças císticas.

O diagnóstico definitivo dessa enfermidade só pode ser obtido através da análise histopatológica das lesões, e a identificação da espécie. As etapas sugeridas por D'Alessandro ${ }^{6}$ para o estabelecimento de uma hipótese de HP, são: 1) a demonstração de uma massa policística seja por exame físico ou por métodos de imagem (ultrasonografia ou tomografia computadorizada);2) procedência de uma área silvestre, com hábitos relacionados ao uso de animais selvagens como fonte alimentar; 3) sorologia utilizando métodos imunoenzimáticos, como enzymelinked immunoassay (ELISA), hemaglutinação indireta ou contraimunoeletroforese $312 \mathrm{e}, 4$ ) análise histopatológica, para confirmação das características morfológicas das larvas ${ }^{20}$
Os casos descritos nesse relato foram diagnosticados obedecendo aos critérios sugeridos por D'Alessandro em 1997. Seguem os padrões da hidatidose policística apresentados na literatura. Acometendo indivíduos jovens, com sintomatologia preponderantemente abdominal, revelando lesões policísticas nos órgãos alvos, predominantemente em fígado (geralmente no lobo direito). Ambos apresentaram como início do quadro hepatomegalia e icterícia colestática. Não se utilizou a histopatologia, que confirmaria a etiologia.

Considerando-se o imunodiagnóstico várias técnicas têm sido empregadas nas hidatidoses ${ }^{12}$. Desde a intradermo-reação (Casoni), fixação de complemento, hemaglutinação indireta, imunofluorescência, difusão em gel, imunoeletroforese, floculação da bentonita, aglutinação com látex, teste imunoenzimático (Enzymelinked immunosorbent assay-ELISA).

Arienti e cols.em $1997^{3}$, compararam a contraimunoeletroforese (CIE) com o teste ELISA no diagnóstico da hidatidose unilocular. A sensibilidade do ELISA foi 95\% em 176 pacientes, enquanto a CIE apresentou sensibilidade de $55 \%$ elevando para $68 \%$ quando o órgão atingido era o fígado. O ELISA resultou em alguns falsos negativos o que não ocorreu com a $\mathrm{CIE}$, mostrando sua alta especificidade.

Nos casos apresentados pode-se classificar o resultado do tratamento com albendazol como sucesso parcial, garantindo apenas que não houvesse evolução do quadro clínico, mas apresentando recidiva em mais de uma ocasião logo que interrompido o tratamento. Isto tem feito com que os pacientes usem albendazol continuamente, diferente do proposto na literatura ${ }^{16}$.

A importância deste relato reside no fato de se estar iniciando o reconhecimento de dois casos de HP em uma mesma área geográfica, sugerindo a necessidade de estudos epidemiológicos que determinem a freqüência dessa enfermidade na população.

\section{AGRADECIMENTOS}

Somos gratos ao Serviço de Doenças Infecciosas e Parasitárias do Hospital Geral de Clínicas de Rio Branco-Acre, pelas informações e pelo trabalho dedicado à especialidade no Estado. Ao Prof Dr Roberto Martinez e sua equipe da Faculdade de Medicina da Universidade de São Paulo em Ribeirão Preto (USP-RP), pela realização dos testes sorológicos.

\section{REFERÊNCIAS BIBLIOGRÁFICAS}

1. Almeida SCX, Martins RLM, Moraes MAP, Viegas CA, Grillo M. Hidatidose pulmonar policística mimetizando lesões metastáticas: relato de caso.Jornal de Pneumologia 23: 261-263,1997.

2. Amaral ISA, Soares MC, Boulhosa CF e Amaral EAA. Hidatidose policística por E.vogeli Ilha do Marajó, Pará, Brasil Acompanhamento clínico de três anos. Revista Paraense de Medicina 14:48-53,2000.

3. Arienti HM, Guignard SI, Rinaldi DE, Elbarcha OC. Comparison of two serologic methods for the diagnosis of hydatidosis. Revista Panamericana de Salud Pública 1:376-80,1997.

4. Carmona C, Perdomo R, Carbo A, Alvarez C, Monti J, Grauerb R, Stern D, Perera G, Lloyd S, Bazini R, Gemmell A, Yarzabal L.Risk factors associated with human cystic echinococcosis in Florida, Uruguay: Results of a mass screening study using ultrasound and serology. American Journal of Tropical Medicine and Hygiene 58: 599-605,1998. 
5. D'Alessandro A. Polycistic echinococcosis in tropical America: Echinococcus vogeli and E. oligarthrus. Acta Tropica 67: 43-65,1997.

6. D'Alessandro A, Moraes MAP and Raick AN. Polycystic hydatid disease in Brazil. Report of five new human cases and a short review of other published observations. Revista da Sociedade Brasileira de Medicina Tropical 29: 219-228,1996.

7. D’Alessandro A, Ramirez LE, Chapadeiro E, Lopes ER, Mesquita PM. Second recorded case of human infection by Echinococcus oligarthrus. American Journal Tropical Medicine Hygiene 52: 29-33,1995.

8. D’Alessandro A, Rausch RL, Cuello C, Aristizabal N. Echinococcus vogeli in man, with a review of polycystic hydatid disease in Colombia and neighboring countries. American Journal of Tropical Medicine and Hygiene 28: 303-317,1979.

9. D'Alessandro A, Rausch RL, Morales GA, Collet S, Angel D. Echinococcus Infections in Colombian Animals. American Journal Tropical Medicine Hygiene $30: 1263-1276,1981$.

10. Ferreira MS, Nishioka SA, Rocha A, D'Alessandro A. Echinococcus vogeli polycystic hydatid disease: report of two Brazilian cases outside the Amazon region. Transactions of the Royal Society of Tropical Medicine and Hygiene 89: 286-287,1995.

11. Ferreira MS, Rocha A, Gonçalves EG, Carvalho AM, Nishioka SA, Andrade NB Relato de Caso: Um caso de hidatidose policística autóctone de Minas Gerais, Brasil. Revista da Sociedade Brasileira de Medicina Tropical 20(3): 181-186, 1987.

12. Gottstein B, D'Alessandro A, Rausch RL. Immunodiagnosis of polycystic hydatid disease/polycystic echinococcosis due to Echinococcus vogeli. American Journal Tropical Medicine Hygiene 53: 558-563,1995.

13. Larrieu E, Costa MT, Cantoni G, Labanchi JL, Bigatti R, Pérez A, Araya D, Mancini S, Herrero E, Talmon G, Romeo S, Thakur A. Control program of hydatid disease in the province of Río Negro, Argentina. 1980-1997. Boletin Chileno de Parasitologia 5:49-53, 2000.

14. Meneghelli UG. Calcificações Hepáticas Múltiplas Decorrentes de Doença Hidática Policística. Revista Goiana Médica 31: 53-60,1985.

15. Meneghelli UG, Barbó MLP, Magro JE, Bellucci AD and Velludo Llorach MA. Polycystic hydatid disease (Echinococcus vogeli): Clinical and radiological manifestations and treatment with Albendazole of a patient from the Brazilian Amazon region. Arquivos de Gastroenterologia de São Paulo 23: 177-183,1986.

16. Meneghelli UG, Martinelli ALC, Belluci AD, Villanova MG. Polycystic hydatid disease (Echinococcus vogeli). Treatment with albendazole. Annals of Tropical Medicine and Parasitology 86:152-156,1992a.

17. Meneghelli UG, Martinelli ALC, Llorach Velludo MAS. Cistos de Echinococcus vogeli em fígado de paca (Cuniculus paca) originária do Estado do Acre, Brasil. Revista da Sociedade Brasileira de Medicina Tropical 23:153-155,1990.

18. Meneghelli U.G, Martinelli A.L.C, Velludo Llorach M.A, Bellucci A.D, Magro J.E, Barbó M.L.P. Polycystic hydatid disease (Echinococcus vogeli) Clinical, laboratory and morphological findings in nine Brazilian patients. Journal of Hepatology 14: 203-210, 1992b.

19. Pires J.A.A, Pereira G.B, Pastore R, Lauria-Pires L. Doença hepática policística. Jornal Brasileiro de Patologia 37:90,2001.

20. Rausch RL, D'Alessandro A. Histogenesis in the metacestode of Echinococcus vogeli and mechanism of pathogenesis in polycystic hydatid disease. Journal of Parasitology 85:410-418,1999.

21. Schaefer JW, Khan. MY. Echinococcosis (Hydatid disease): Lessons from experience with 59 patients. Reviews of Infectious Diseases 13: 243-247,1991. 